\title{
ChemComm
}

\section{Nanopapers for organic solvent nanofiltration $\dagger$} Cite this: Chem. Commun., 2014,
50, 5778

Received 19th January 2014,

Accepted 31st March 2014

DOI: $10.1039 / c 4 c c 00467 a$

www.rsc.org/chemcomm

\author{
A. Mautner, ${ }^{a}$ K.-Y. Lee, ${ }^{\text {bc }}$ P. Lahtinen, ${ }^{d}$ M. Hakalahti, ${ }^{d}$ T. Tammelin, ${ }^{d}$ K. Li ${ }^{e}$ and \\ A. Bismarck ${ }^{\star a c}$
}

\begin{abstract}
Would it not be nice to have an organic solvent nanofiltration membrane made from renewable resources that can be manufactured as simply as producing paper? Here the production of nanofiltration membranes made from nanocellulose by applying a papermaking process is demonstrated. Manufacture of the nanopapers was enabled by inducing flocculation of nanofibrils upon addition of trivalent ions.
\end{abstract}

Organic solvent nanofiltration (OSN) has found both widespread scientific and industrial interest since its emergence at the beginning of this century. ${ }^{1}$ OSN describes the process of separating molecules or particles with a molecular weight $\left(M_{\mathrm{W}}\right)$ of some hundreds to thousands of $\mathrm{Da}-$ i.e. particles or molecules with nanometer dimensions - from an organic solvent. ${ }^{1,2}$ Applications such as product purification and concentration, solvent exchange and recycling as well as recovery of homogeneous catalysts have been reported and compared favorably to classical methods, such as distillation, due to the lower energy consumption and milder conditions that chemical compounds experience during separation. ${ }^{2}$ However, the utilization of organic solvents in NF operations still provides a significant challenge for the membranes from the materials point of view, in particular due to the required solvent-stability, which many traditional polymer membranes lack. $^{3}$ Several different engineering and high performance polymers have been tested for OSN membranes. ${ }^{3-5}$ Typically,

\footnotetext{
${ }^{a}$ Department of Chemical Engineering, Polymer \& Composite Engineering (PaCE) Group, Imperial College London, South Kensington Campus, SW7 2AZ London, UK. E-mail: a.bismarck@imperial.ac.uk; Fax: +44 (o)20759 45638; Tel: +44 (0)20759 45578

${ }^{b}$ Department of Chemical Engineering, University College London, Torrington Place, WC1E $7 J E$ London, UK

${ }^{c}$ Polymer \& Composite Engineering (PaCE) group, Institute for Materials Chemistry and Research, Faculty of Chemistry, University of Vienna, Währingerstraße 42, A-1090 Vienna, Austria. E-mail: alexander.bismarck@univie.ac.at

${ }^{d}$ VTT Technical Research Centre of Finland, Biologinkuja 7, FL-02044 Espoo, Finland

${ }^{e}$ Department of Chemical Engineering, Imperial College London, South Kensington Campus, SW7 2AZ London, UK

$\dagger$ Electronic supplementary information (ESI) available: Further characterisation of the membranes and membrane compaction. See DOI: 10.1039/c4cc00467a
}

polymer membranes do require a mechanical support, which is often made of polyamides, polysulfones or polyimides. ${ }^{6}$ Besides polymer membranes, ceramics ${ }^{7}$ or organic-inorganic hybrid materials ${ }^{8}$ have been explored. Unfortunately, all these materials suffer from drawbacks; the production processes involve the use of large quantities of solvents and chemicals as well as extensive energy usage in the case of ceramics. ${ }^{9}$ Thus, simple, clean and fast production processes would be desirable to manufacture solvent stable nanofiltration membranes.

In general, both everyday life and laboratory operations depend on filtration processes that are performed using membranes or cellulose filters. However, there are certain limitations when it comes to the removal of small $M_{\mathrm{W}}$ compounds using filter papers. In recent years, nanofibrillated cellulose (NFC) has gained significant attention due to its outstanding mechanical and chemical properties, ${ }^{10}$ especially when used in composites. ${ }^{11} \mathrm{NFC}$, when used in the paper form, also known as nanopaper, possesses outstanding mechanical properties, low thermal expansion coefficients, high optical transparency and good gas barrier properties. ${ }^{12-15}$ These barrier properties have been exploited in food packaging films. ${ }^{16}$ Nanopapers might offer potential for applications in separation processes due to their inherent pore dimensions in the nm range. ${ }^{13}$ For example, the NFC paper was explored as a separator in Li-ion batteries. ${ }^{17}$

Here we introduce solvent stable nanofiltration (NF) membranes entirely made from nanocellulose. These membranes are produced by a papermaking process that utilizes an aqueous suspension of nanocellulose thus avoiding vast amounts of organic solvents that are usually necessary for the production of conventional OSN polymer membranes. ${ }^{5}$ Manufacture of these nanopapers is enabled by inducing flocculation of nanofibrils upon addition of multivalent ions. This type of nanocellulose membrane represents a step forward within this important domain and demonstrates the utilization of a well-known material for an advanced application.

We discuss the use of nanopapers made entirely from (2,2,6,6-tetramethylpiperidin-1-yl)oxy (TEMPO) oxidized NFC (herein termed as NFC-O) with fibre diameters ranging from 5 to $30 \mathrm{~nm}$ (UPM-Kymmene Oyj, Helsinki, Finland) for NF 
membranes. The production method of NFC-O is described in detail elsewhere. ${ }^{18}$ It can be anticipated that these nanofibrils can be densely compacted to form a framework structure with pore-dimensions in the range of the diameter of the nanofibrils. This concept has been mathematically proven by Zhang. ${ }^{19}$ To demonstrate the possibility of controlling the pore size, and thus the molecular weight cut-off (MWCO) and permeance of the nanocellulose membranes, we also used another NFC grade produced by mechanical grinding (MKZA10-15J Supermasscolloider, Masuko Sangyo Co., Kawaguchi, Japan) of never-dried bleached kraft birch pulp as described by Lee et al. ${ }^{14}$ Herein, we call these fibrils NFC-K, which possess fibre diameters of 50 to $100 \mathrm{~nm}$ (more details about the NFC grades can be found in the ESI $\dagger$ ).

In general, for the production of paper, cellulose fibres are suspended in water. This suspension is then filtered, the resulting filter cake, i.e. the fibre mat, is pressed and water is removed until the desired quality is achieved. As for usual paper, the production of nanopapers started from an NFC in water suspension with a consistency of $0.3 \mathrm{wt} \%$. This suspension was produced by blending (Breville VBL065-01, Oldham, UK) NFC feedstock for $2 \mathrm{~min}$, which had an original consistency of $2.5 \mathrm{wt} \%$ and $1.8 \mathrm{wt} \%$, respectively, for NFC-O and NFC-K. Nanopapers with the desired grammage were produced by vacuum-filtration of NFC suspensions containing a pre-determined amount of nano-cellulose onto cellulose filter papers (VWR 413, 5-13 $\mu \mathrm{m}$ pore size, Lutterworth, UK). However, we observed that NFC-O passed through both the filter paper and the supporting glass frit (Schott, porosity No. 1, Mainz, Germany) due to its extremely small size. This effect was not observed for the filtration of the larger diameter NFC-K fibrils, which was consistent with our previous observations. ${ }^{14}$ In order to facilitate the filtration of NFC-O, flocculation of the fibrils by changing the surface charge was required. Thus, we measured the $\zeta$-potential of NFC as function of pH in a $1 \mathrm{mM} \mathrm{KCl}$ electrolyte using electrophoresis (Brookhaven ZetaPALS analyzer, Holtsville, USA). It can be inferred from the $\zeta=f(\mathrm{pH})$ curve that it is impossible to induce flocculation of NFC-O by changing the $\mathrm{pH}$ of the NFC-O suspension, since the isoelectric point (iep), where $\zeta=0$, at which significant flocculation would occur, is very low (Fig. 1, left). To reach the iep, a $\mathrm{pH}$ of 1.5 (extrapolated) would be required, which could possibly result in acid hydrolysis of NFC. ${ }^{20}$

The $\zeta$-potential as a measure of surface charge is dependent on the ionic strength, which is most effectively increased by addition of multivalent ions. Therefore, we measured $\zeta$ as a function of the salt $\left(\mathrm{MgCl}_{2}\right.$ and $\left.\mathrm{AlCl}_{3}\right)$ concentration, from which the point of zero charge (pzc) was determined (Fig. 1, right).
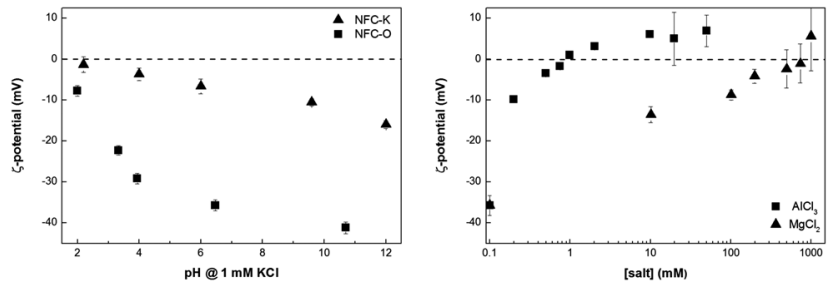

Fig. $1 \zeta$-potential of NFC-O and $-\mathrm{K}$ in $1 \mathrm{mM} \mathrm{KCl}$ aqueous solution as a function of $\mathrm{pH}$ (left) and of $\mathrm{NFC}-\mathrm{O}$ as a function of $\mathrm{MgCl}_{2}$ and $\mathrm{AlCl}_{3}$ concentrations (right).
At the pzc, the NFC-O fibrils have zero net surface charge and, therefore, no electrostatic repulsion exists between NFC-O fibrils, which causes the whole NFC-O suspension to form a single gel. Multivalent cations specifically adsorb on negatively charged NFC-O surfaces causing the $\zeta$-potential to decrease by effectively reducing the Debye length. Ultimately, the pzc was reached upon adjusting the electrolyte concentration to $800 \mathrm{mM}$ for $\mathrm{MgCl}_{2}$ and $1 \mathrm{mM}$ for $\mathrm{AlCl}_{3}$, respectively (Fig. 1, right), because the ionic strength of the electrolyte increases exponentially with increasing charge of the cations. To produce NFC-O filter cakes, $\mathrm{AlCl}_{3}$ was added to achieve a concentration of $1 \mathrm{mM}$.

Wet NFC-O and -K filter cakes of $125 \mathrm{~mm}$ in diameter were pressed between blotting papers (Whatman 3MM Chr, Kent, UK) for $5 \mathrm{~min}$ under a weight of $10 \mathrm{~kg}$ to increase the NFC solid content to $15 \mathrm{wt} \%$. These filter cakes were then sandwiched between blotting papers and metal plates for further hot pressing at $120{ }^{\circ} \mathrm{C}$ for $1 \mathrm{~h}$ under a weight of $1 \mathrm{t}$ to dry and consolidate the filter cakes. The hot pressing also prevents the shrinkage of nanopapers and increases the density of the sheets, resulting in better mechanical properties of the papers. ${ }^{15}$ Nanopapers with grammages between 10 and $70 \mathrm{~g} \mathrm{~m}^{-2}$ (gsm) were produced from both types of nanocelluloses. The thickness of these nanopapers was found to increase linearly with the grammage (Fig. S1, ESI $\dagger$ ). The nanopapers produced were used as membranes directly.

Exemplarily, the permeance $(P)$ of tetrahydrofuran (THF), $n$-hexane and water through the nanopapers was measured in a dead end cell (Sterlitech HP 4750, Kent, USA). The solvent was forced through the nanopapers at $20{ }^{\circ} \mathrm{C}$ by nitrogen at a head pressure of $0.2 \mathrm{MPa}$ and $1 \mathrm{MPa}$ for nanopapers with grammages $<20 \mathrm{gsm}$ and $>20$ gsm, respectively. The amount of solvent that passed through the nanopaper for a given time interval was measured gravimetrically and used to determine $P\left[\mathrm{~L} \mathrm{~m}{ }^{-2} \mathrm{~h}^{-1} \mathrm{MPa}^{-1}\right]$. For these measurements, discs of $49 \mathrm{~mm}$ in diameter were cut from the nanopapers and placed in the dead end cell on a ceramic support. In the beginning of the measurement, $P$ decreased significantly (Fig. S2, ESI $\dagger$ ) caused by membrane compaction due to the applied pressure. ${ }^{21}$

The permeance of different solvents is exemplarily shown for NFC-O nanopapers in Fig. 2(a). These measurements showed that $P$ of the tested solvents passed through nanopapers increases in the following order: water $<$ THF $<n$-hexane. Thus, irrespective of the hydrophilic nature of nanocellulose and the hydrophobicity of some of the solvents, $P$ increases inversely with increasing hydrophobicity of the solvent. It should be noted
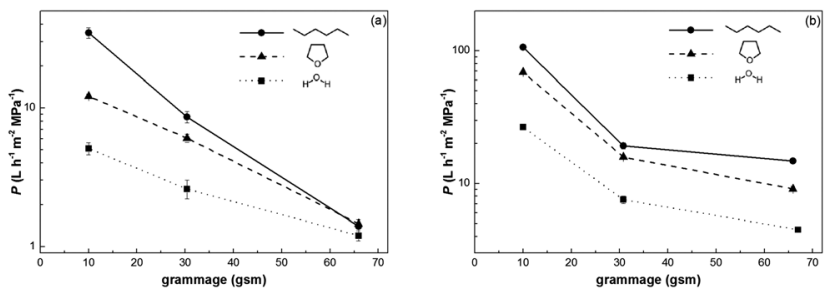

Fig. 2 Permeance $P$ of different solvents for NFC-O (a) and NFC-K (b) nanopapers of different grammages. 
that the calculation of $P$ does not take into account the viscosity of the solvent.

In addition to this, we also observed that $P$ is dependent on the grammage, and thus the thickness, of the nanopapers as well as the diameter of the fibrils (Fig. 2). Using nanofibrils with larger diameters (NFC-K) for membrane fabrication resulted in nanopapers with larger pore dimensions as compared to NFC-O, which, in conjunction with varying the grammage of the nanopapers, allows the permeance to be controlled over a wide range. Varying the aspect ratio of randomly packed high aspect ratio cylinders hardly affects the porosity of a mat. ${ }^{22}$ Since the number of fibrils per unit mass within the same volume element is higher for smaller fibrils, this results in a larger number of pores, which are smaller in diameter due to the constant porosity (around 35\%).

The nanofiltration membrane performance is generally quantified by the MWCO, which was determined by passing standard polymer solutions of known concentrations through the nanopapers. The amount of rejected polymer molecules was quantified using gel permeation chromatography (GPC, aqueous: Viscotek GPCmax VE2001, VE3580 RI detector, Malvern, UK; organic: Waters 515 HPLC pump, Waters 2410 RI detector, Milford, USA). The MWCO is defined as the molecular weight of a molecule which is rejected by $90 \% .^{23}$ Poly(ethylene glycol) (PEG) dissolved in deionized water and polystyrene (PS) standards dissolved in THF with molecular weights ranging from 1 to $13 \mathrm{kDa}$ were used to determine the MWCO for NFC-O nanopapers with a grammage of $65 \mathrm{gsm}$. The retention of PEG and PS standards as a function of the $M_{\mathrm{W}}$ is shown in Fig. 3(a).

For PS and PEG, the MWCO values were found to be $3.2 \mathrm{kDa}$ and $6 \mathrm{kDa}$, corresponding to hydrodynamic radii of $1.6 \mathrm{~nm}^{24}$ and $2.4 \mathrm{~nm},{ }^{25}$ respectively, which represent the pore size. Thus, our nanopaper membranes have a MWCO at the upper end of the NF range. In the case of NFC-K papers (Fig. 3(b)), the MWCO of PEG was $25 \mathrm{kDa}$, which corresponds to a hydrodynamic radius of $5 \mathrm{~nm}$ (ref. 25) and for PS it was $40 \mathrm{kDa}$, which is equivalent to a hydrodynamic radius of $5.5 \mathrm{~nm}^{24}$ This demonstrated that by using differently sized cellulose nanofibrils, around $50 \mathrm{~nm}$ for NFC-K and down to $5 \mathrm{~nm}$ for NFC-O, it is possible to adjust the pore dimensions of the resulting nanopapers, which is due to a reduced pore size in the random packing of cylinders with smaller diameters.

To summarize, we produced nanocellulose based nanofiltration membranes by simply using a papermaking process. These nanopapers are suitable for NF of organic solvents and
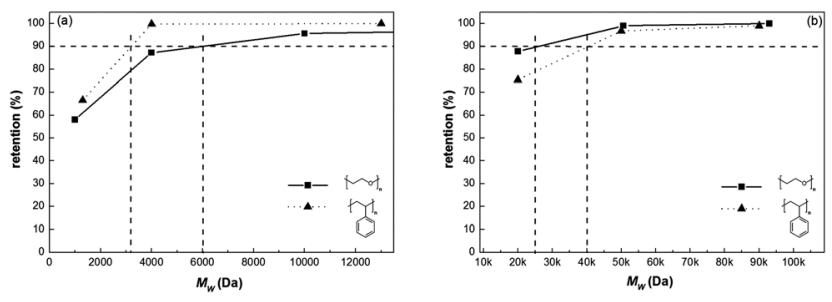

Fig. 3 Retention of PS \& PEG $=f\left(M_{W}\right)$ for NFC-O (a) and NFC-K (b) nanopapers: MWCO is the molecular weight of which $90 \%$ is rejected. water. It was observed that the permeance of nanopapers was dependent on the hydrophilicity of the solvents and that $P$ was governed by the grammage of the nanopapers and the dimensions of the nanofibrils. We also observed that the MWCO was determined by the diameter of the nanofibrils, which affects the pore dimensions of the nanopapers. It is thus possible to tailor the membrane performance over a wide range of applications by selecting nanofibrils with different diameters. In conclusion, we can prepare, as simply as making paper, solvent-stable OSN membranes from renewable resources. If it eventually becomes possible to produce NFC with fibrils of evenly distributed lengths, potentially even thinner active membrane layers with smaller MWCO could be created, which would drastically improve the performance of these types of NF membranes.

The authors greatly acknowledge the funding provided by the EU FP7 project NanoSelect (Grant No. 280519) and the University of Vienna for funding KYL. We thank Maria Schachner (TU Vienna) and Dr Ivan Zadrazil (Imperial) for performing the GPC-measurements.

\section{Notes and references}

1 P. Vandezande, L. E. M. Gevers and I. F. J. Vankelecom, Chem. Soc. Rev., 2008, 37, 365-405.

2 R. Othman, A. W. Mohammad, M. Ismail and J. Salimon, J. Membr. Sci., 2010, 348, 287-297; A. G. Livingston, L. Peeva, S. Han, D. Nair, S. S. Luthra, L. S. White and L. M. Freitas Dos Santos, Ann. N. Y. Acad. Sci., 2003, 984, 123-141; D. Peshev, L. G. Peeva, G. Peev, I. I. R. Baptista and A. T. Boam, Chem. Eng. Res. Des., 2011, 89, 318-327; M. Priske, K.-D. Wiese, A. Drews, M. Kraume and G. Baumgarten, J. Membr. Sci., 2010, 360, 77-83; A. Cano-Odena, P. Vandezande, D. Fournier, W. Van Camp, F. E. Du Prez and I. F. J. Vankelecom, Chem. - Eur. J., 2010, 16, 1061-1067; J. C.-T. Lin and A. G. Livingston, Chem. Eng. Sci., 2007, 62, 2728-2736; L. S. White and C. R. Wildemuth, Ind. Eng. Chem. Res., 2006, 45, 9136-9143.

3 M. Sairam, X. X. Loh, K. Li, A. Bismarck, J. H. G. Steinke and A. G. Livingston, J. Membr. Sci., 2009, 330, 166-174.

4 X. Li, P. Vandezande and I. F. J. Vankelecom, J. Membr. Sci., 2008, 320, 143-150; X. X. Loh, M. Sairam, J. H. G. Steinke, A. G. Livingston, A. Bismarck and L. Kang, Chem. Commun., 2008, 6324-6326; M. Peyravi, A. Rahimpour and M. Jahanshahi, J. Membr. Sci., 2012, 423-424, 225-237; H. Siddique, L. G. Peeva, K. Stoikos, G. Pasparakis, M. Vamvakaki and A. G. Livingston, Ind. Eng. Chem. Res., 2013, 52, 1109-1121; S. Zeidler, U. Kätzel and P. Kreis, J. Membr. Sci., 2013, 429, 295-303.

5 I. Soroko, Y. Bhole and A. G. Livingston, Green Chem., 2011, 13, 162-168.

6 M. F. Jimenez-Solomon, P. Gorgojo, M. Munoz-Ibanez and A. G. Livingston, J. Membr. Sci., 2013, 448, 102-113; M. F. Jimenez Solomon, Y. Bhole and A. G. Livingston, J. Membr. Sci., 2012, 423-424, 371-382.

7 A. Buekenhoudt, F. Bisignano, G. De Luca, P. Vandezande, M. Wouters and K. Verhulst, J. Membr. Sci., 2013, 439, 36-47; P. Marchetti, A. Butté and A. G. Livingston, J. Membr. Sci., 2012, 415-416, 444-458.

8 F. Peng, L. Lu, H. Sun, Y. Wang, J. Liu and Z. Jiang, Chem. Mater., 2005, 17, 6790-6796; T. C. Merkel, B. D. Freeman, R. J. Spontak, Z. He, I. Pinnau, P. Meakin and A. J. Hill, Science, 2002, 296, 519-522.

9 K. Li, Ceramic Membranes for Separation and Reaction, John Wiley \& Sons, Ltd., Chichester, UK, 2007.

10 P. Chen, S. Y. Cho and H.-J. Jin, Macromol. Res., 2010, 18, 309-320; D. Klemm, F. Kramer, S. Moritz, T. Lindstroem, M. Ankerfors, D. Gray and A. Dorris, Angew. Chem., Int. Ed., 2011, 50, 5438-5466.

11 J. J. Blaker, K.-Y. Lee and A. Bismarck, J. Biobased Mater. Bioenergy, 2011, 5, 1-16; S. J. Eichhorn, A. Dufresne, M. Aranguren, N. E. Marcovich, J. R. Capadona, S. J. Rowan, C. Weder, W. Thielemans, M. Toman, S. Renneckar, W. Gindl, S. Veigel, 
J. Keckes, H. Yano, K. Abe, M. Nogi, A. N. Nakagaito, A. Mangalam, J. Simonsen, A. S. Benight, A. Bismarck, L. A. Berglund and T. Peijs, J. Mater. Sci., 2010, 45, 1-33.

12 S.-J. Chun, S.-Y. Lee, G.-H. Doh, S. Lee and J. H. Kim, J. Ind. Eng. Chem., 2011, 17, 521-526; A. Dufresne, Nanocellulose: From Nature to High Performance Tailored Materials, Walter de Gruyter \& Co, Berlin/ Boston, 2012; J. Gutierrez, S. C. M. Fernandes, I. Mondragon and A. Tercjak, ChemSusChem, 2012, 5, 2323-2327; L. Hu, G. Zheng, J. Yao, N. Liu, B. Weil, M. Eskilsson, E. Karabulut, Z. Ruan, S. Fan, J. T. Bloking, M. D. McGehee, L. Wagberg and Y. Cui, Energy Environ. Sci., 2013, 6, 513-518; J. Huang, H. Zhu, Y. Chen, C. Preston, K. Rohrbach, J. Cumings and L. Hu, ACS Nano, 2013, 7, 2106-2113.

13 M. Henriksson, L. A. Berglund, P. Isaksson, T. Lindstroem and T. Nishino, Biomacromolecules, 2008, 9, 1579-1585.

14 K.-Y. Lee, T. Tammelin, K. Schulfter, H. Kiiskinen, J. Samela and A. Bismarck, ACS Appl. Mater. Interfaces, 2012, 4, 4078-4086.

15 M. Österberg, J. Vartiainen, J. Lucenius, U. Hippi, J. Seppälä, R. Serimaa and J. Laine, ACS Appl. Mater. Interfaces, 2013, 5, 4640-4647.
16 A. Khan, T. Huq, R. A. Khan, B. Riedl and M. Lacroix, Crit. Rev. Food Sci. Nutr., 2012, 54, 163-174.

17 S.-J. Chun, E.-S. Choi, E.-H. Lee, J. H. Kim, S.-Y. Lee and S.-Y. Lee, J. Mater. Chem., 2012, 22, 16618-16626.

18 WO Pat., WO 2012/168562 A1, 2012.

19 W. Zhang, PhD thesis, Louisiana State University, 2006.

20 J. F. Saeman, Ind. Eng. Chem., 1945, 37, 43-52.

21 E. Gibbins, M. D'Antonio, D. Nair, L. S. White, L. M. Freitas dos Santos, I. F. J. Vankelecom and A. G. Livingston, Desalination, 2002, 147, 307-313.

22 M. Novellani, R. Santini and L. Tadrist, Eur. Phys. J. B, 2000, 13, 571-578.

23 Y. H. See Toh, X. X. Loh, K. Li, A. Bismarck and A. G. Livingston, J. Membr. Sci., 2007, 291, 120-125.

24 E. Uliyanchenko, P. J. Schoenmakers and S. van der Wal, J. Chromatogr. A, 2011, 1218, 1509-1518.

25 J. K. Armstrong, R. B. Wenby, H. J. Meiselman and T. C. Fisher, Biophys. J., 2004, 87, 4259-4270. 